\title{
UPCommons
}

Portal del coneixement obert de la UPC

http://upcommons.upc.edu/e-prints

Aquesta és una còpia de la versió draft d'un article publicat a

\section{Solar energy materials and solar cells}

http://hdl.handle.net/2117/104004

Almora, O, Gerling Sarabia, L., Voz, C., Alcubilla, R., Puigdollers, J. Garcia-Belmonte, G. Superior performance of V2O5 as hole selective contact over other transition metal oxides in silicon heterojunction solar cells. "Solar energy materials and solar cells", 1 Agost 2017, vol. 168, p. 221-226. DOI 10.1016/j.solmat.2017.04.042 


\section{Superior Performance of $\mathrm{V}_{2} \mathrm{O}_{5}$ as Hole Selective Contact over other Transition Metal Oxides in Silicon Heterojunction Solar Cells}

Osbel Almora ${ }^{1}$, Luis G. Gerling ${ }^{2,3}$, Cristóbal Voz $^{2}$, Ramón Alcubilla ${ }^{2,3}$, Joaquim Puigdollers $^{2,3, *}$, and Germà Garcia-Belmonte ${ }^{1, *}$

${ }^{1}$ Institute of Advanced Materials (INAM), Universitat Jaume I, 12006 Castelló, Spain

2 Electronic Engineering Department, Universitat Politècnica de Catalunya, Jordi Girona 1-3, Barcelona 08034, Spain

${ }^{3}$ Centre de Recerca en Nanoenginyeria (CrNE), Pascual Vila 15, Barcelona 08028, Spain

\section{Abstract}

Transition metal oxides (TMOs) have recently been proved to efficiently serve as hole-selective contacts in crystalline silicon (c-Si) heterojunction solar cells. In the present work, two TMO/c-Si heterojunctions are explored using $\mathrm{MoO}_{3}$ (reference) and $\mathrm{V}_{2} \mathrm{O}_{5}$ as an alternative candidate. It has been found that $\mathrm{V}_{2} \mathrm{O}_{5}$ devices present larger (16\% improvement) power conversion efficiency mainly due to their higher open-circuit voltage. While $\mathrm{V}_{2} \mathrm{O}_{5} / \mathrm{c}$-Si devices with textured front surfaces exhibit larger short-circuit currents, it is also observed that flat solar cell architectures allow for passivation of the $\mathrm{V}_{2} \mathrm{O}_{5} / \mathrm{n}$-Si interface, giving significant carrier lifetimes of $200 \mu$ s (equivalent to a surface recombination velocity of $S_{\text {eff }} \sim 140 \mathrm{~cm} \mathrm{~s}^{-1}$ ) as derived from impedance analysis. As a consequence, a significant open-circuit voltage of $662 \mathrm{mV}$ is achieved. It is found that, at the TMO/c-Si contact, a TMO work function enhancement $\Delta \Phi_{T M O}$ occurs during the heterojunction formation with its consequent dipole layer enlargement $\Delta^{\prime}=\Delta+\Delta \Phi_{T M O}$. Our results provide new insights into the TMO/c-Si contact energetics, carrier transport across the interface and surface recombination allowing for further understanding of the nature of TMO/c-Si heterojunctions.

Keywords: Transition metal oxides, silicon solar cells, impedance spectroscopy, passivation, minority carrier lifetime.

*Corresponding authors:

J. Puigdollers, (joaquim.puigdollers@upc.edu)tel.:+34 934011002

G. Garcia-Belmonte, (garciag@uji.es) tel.: +34 964387538

3 May 2017 


\section{Introduction}

During the last decade, crystalline silicon (c-Si) heterojunction solar cells incorporating thin films of hydrogenated amorphous silicon $(\mathrm{a}-\mathrm{Si}: \mathrm{H})$ have become the state-of-the-art photovoltaic technology, achieving record efficiencies above 26\% [1]. The key for the success of this technology lies on the superior surface passivation provided by very thin layers $(<5 \mathrm{~nm})$ of intrinsic a-Si:H, also allowing for carrier conduction with minimal resistive losses. However, performance limitations caused by the relatively high optical absorption of a-Si:H [2] and the highly recombining $n / p$ doped layers [3] (which act as electron/hole selective contacts) have led to investigate novel heterojunction concepts between $\mathrm{c}$-Si and dopant-free highly-transparent transition metal oxides (TMOs) [4, 5].

Originally introduced in organic electronics as electron and hole transport layers, TMOs are large band gap $\left(E_{\mathrm{g}}>3 \mathrm{eV}\right)$ semiconductors with a wide variety of work functions $\left(\Phi_{T M O} \sim 3-7 \mathrm{eV}\right)$ and conductivities (from insulating to metallic-like), providing great flexibility when used as electron- or hole-selective contact materials [6]. Additionally, they can be deposited at low temperature $\left(T<200^{\circ} \mathrm{C}\right)$ or by solutionprocessing methods [7], increasing the potential for process simplification and cost reduction. Until now, hole-selective $\mathrm{MoO}_{3}$ has been the study-case TMO material alongside n-type crystalline silicon (n-Si), reaching a power conversion efficiency (PCE) of $22.5 \%$ in a $\mathrm{MoO}_{3} /(\mathrm{i}) \mathrm{a}-\mathrm{Si}: \mathrm{H} / \mathrm{n}-\mathrm{Si}$ configuration [8], where the intrinsic (i)a-Si:H chemically passivates the silicon surface while $\mathrm{MoO}_{3}$ provides the hole-selectivity. Also rear $\mathrm{MoO}_{x}$ contacts with partial contact areas have been reported with an efficiency of 20.4\% [9]. As an alternative, simpler structures comprising TMOs in direct contact with n-Si have also been proposed, achieving efficiencies between 12.5 and 18.4\% [10-12].

The unique behavior of $\mathrm{MoO}_{3}$ and other similar TMOs $\left(\mathrm{V}_{2} \mathrm{O}_{5}, \mathrm{WO}_{3}\right)$ is explained by their electronic configuration and large work function values $\left(\Phi_{T M O}>5.0 \mathrm{eV}\right)$, which upon Fermi level $\left(E_{F}\right)$ alignment with $n-S i\left(\Phi_{\mathrm{n}-\mathrm{Si}} \sim 4.2 \mathrm{eV}\right)$ induces a potential barrier (band bending) $[10,13]$. This is believed to result in the formation of an inversion $\left(\mathrm{p}^{+}\right)$ layer upon n-Si where photogenerated holes are collected and then extracted across the TMO/n-Si interface. Recent reports have also proposed $\mathrm{V}_{2} \mathrm{O}_{5}$ as an interesting alternative to $\mathrm{MoO}_{3}$, indicating that larger open-circuit voltage values (higher holeselectivity) can be achieved for $\mathrm{V}_{2} \mathrm{O}_{5}$-based devices with and without the inclusion of passivating (i)a-Si:H interlayers [10-12].

In the present paper, Impedance Spectroscopy (IS) measurements were used to compare the performance of $\mathrm{MoO}_{3}$ and $\mathrm{V}_{2} \mathrm{O}_{5}$ as hole-selective contacts in n-Si solar cells, showing that $\mathrm{V}_{2} \mathrm{O}_{5}$-based solar cells perform better due to the presence of higher built-in voltages. Additionally, temperature-dependent measurements were used to calculate barrier heights across the interface, giving further details about the energetics of $\mathrm{TMO} / \mathrm{n}-\mathrm{Si}$ heterojunctions. 


\section{Experimental}

Devices Fabrication: Solar cells were fabricated from n-type $2 \Omega \cdot \mathrm{cm}$ resistivity wafers $\left(\sim 2.3 \times 10^{15} \mathrm{~cm}^{-3}\right.$ dopant concentration) made from float zone monocrystalline (100 orientation) material. The use of such high quality silicon allows for a very high bulk lifetime ( $\tau_{\text {bulk }} \sim 3 \mathrm{~ms}$ under high injection conditions), ensuring almost all recombination effects are confined to the surfaces. Solar cells labeled t- $\mathrm{MoO}_{3}$ and t$\mathrm{V}_{2} \mathrm{O}_{5}$ were subjected to random texturization of the front surface by alkaline etching ( $265 \mu \mathrm{m}$ final wafer thickness), while cells named $\mathrm{f}-\mathrm{V}_{2} \mathrm{O}_{5}$ were processed as purchased (flat polished finish, $\sim 280 \mu \mathrm{m}$ wafer thickness). After a standard RCA cleaning 1\% HF dip, all substrates were then loaded into a plasma-enhanced chemical vapor deposition (PECVD) system to deposit on the rear side an electron-selective contact consisting of an intrinsic/n-type a-SiC ${ }_{x}: \mathrm{H}$ stack ( $5 \mathrm{~nm} / 15 \mathrm{~nm}, \chi^{\sim 0.2}$ ). Subsequently, two rear contact strategies were used: 1 ) $\mathrm{t}-\mathrm{MoO}_{3}$ and $\mathrm{t}-\mathrm{V}_{2} \mathrm{O}_{5}$ cells had an a-SiC $\mathrm{X}: \mathrm{H}$ back-reflector $(80 \mathrm{~nm}$, $x \sim 1)$ deposited by PECVD which was then laser-fired to obtain an array of locallydiffused point contacts (0.5\% contacted area) [14]; 2) $\mathrm{f}-\mathrm{V}_{2} \mathrm{O}_{5}$ cells had an indium-tinoxide (ITO) back-reflector/electrode deposited by RF magnetron sputtering ( $80 \mathrm{~nm}$, $1.3 \times 10^{-3} \mathrm{mbar}$ Ar pressure). As for the front hole-selective contacts, $20 \mathrm{~nm}$ thick TMO films were thermally evaporated from powdered $\mathrm{V}_{2} \mathrm{O}_{5} / \mathrm{MoO}_{3}$ sources ( $>99.99 \%$ purity, Sigma Aldrich) at $\sim 8 \times 10^{-6}$ mbar. For the front textured sample, the deposition time was 1.7 times longer than the polished ones, in order to compensate for the increase in surface area. The deposition rate was $\sim 0.2 \AA / s$, as controlled by quartz micro-balance, while the substrate remained at room temperature during the process. After a brief air exposure, an ITO front electrode/antireflective layer $(80 \mathrm{~nm})$ was also deposited. At this point in the process, QSSPC measurements were performed in order to determine the carrier lifetime of the solar cell precursor (figure S5). After lithographic patterning of 1 $\mathrm{cm}^{2}$ active cell areas, a front-contact Ag grid (4.3\% shadow losses) was thermally evaporated by use of a shadow mask, while the back-contact metallization was done by e-beam evaporation of $\mathrm{Ti} / \mathrm{Al}\left(\mathrm{t}-\mathrm{MoO}_{3}\right.$ and $\mathrm{t}-\mathrm{V}_{2} \mathrm{O}_{5}$ ) or Ag evaporation ( $\mathrm{f}-\mathrm{V}_{2} \mathrm{O}_{5}$ ).

Characterizations: The IS measurements at $V_{\text {oc }}$ (Figures S7-S9) were carried out using an Autolab PGSTAT-30 potentiostat in the frequency range between $100 \mathrm{mHz}$ and $1 \mathrm{MHz}$, being the AC perturbation of $10 \mathrm{mV}$. The spectra were recorded in open-circuit conditions under varying illumination up to $150 \mathrm{~mW} \mathrm{~cm}^{-2}$ (XE 300W Newport 6258). For achieving this, a bias voltage which corresponds to $V_{o c}$ was applied, hence ensuring a more homogeneous distribution of excess carriers by suppressing DC current. For practical reasons, an extra loop element was included in series connection with the circuit (Figure 5a), and at some spectra a constant phase element was considered instead of a second capacitor. For the IS measurements at short-circuit in the dark and at different temperatures (Figure S3), a Gamry Reference 3000 potentiostat/galvanostat/ZRA (same AC perturbation and frequency range as above) was employed joining the Novocontrol Quatro Cryosystem. 


\section{Results and discussion}

\subsection{Device structures and performance}

The structure of the three representative devices studied here is presented in the sketches of Figure 1, including the specifications about composition and thickness of each layer. This set of configurations will allow us to properly compare performances among $\mathrm{V}_{2} \mathrm{O}_{5}$ - and $\mathrm{MoO}_{3}$-based Si heterojunction solar cells. The first structure, labeled t- $\mathrm{MoO}_{3}$, uses a $20 \mathrm{~nm}$-thick layer of $\mathrm{MoO}_{3}$ as front hole-selective contact deposited on a textured surface, while the rear electron-selective contact is formed by a $\left(\mathrm{i} / \mathrm{n}^{+}\right) \mathrm{a}-$ $\mathrm{SiC}_{\mathrm{x} \sim 0.2}: \mathrm{H}$ stack that was locally-diffused by laser firing (Figure 1a). On the other hand, there are two structures with $\mathrm{V}_{2} \mathrm{O}_{5}$ as hole selective contact called $t-\mathrm{V}_{2} \mathrm{O}_{5}$ and $\mathrm{f}-\mathrm{V}_{2} \mathrm{O}_{5}$ (see Figures $1 \mathrm{~b}$ and $1 \mathrm{c}$, respectively). While $\mathrm{t}-\mathrm{V}_{2} \mathrm{O}_{5}$ presents the same structure as $\mathrm{t}-$ $\mathrm{MoO}_{3}, \mathrm{f}-\mathrm{V}_{2} \mathrm{O}_{5}$ exhibits a flat superposition of layers, increasing the passivation quality provided by $\mathrm{V}_{2} \mathrm{O}_{5}$. Moreover, $\mathrm{f}-\mathrm{V}_{2} \mathrm{O}_{5}$ uses indium tin oxide (ITO) as a rear electrode, given that laser firing provides a good ohmic contact at the expense of reduced passivation quality. More details about the devices fabrication and morphological features can be found in previous works [10, 15], the experimental section and the Supplementary Information (SI).

(a)

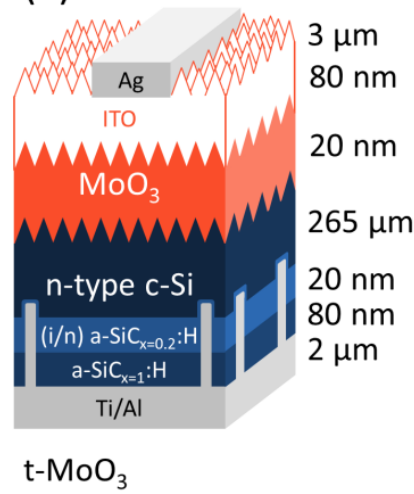

(b)

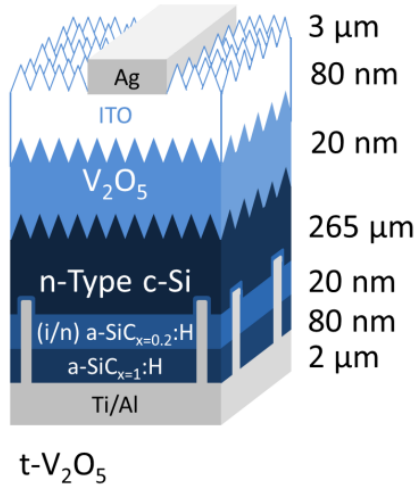

(c)

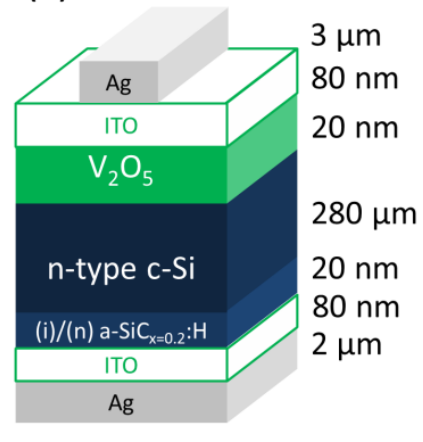

$\mathrm{f}-\mathrm{V}_{2} \mathrm{O}_{5}$

Figure 1: Sketches of the structures for the three devices which were studied in this work, as indicated.

Examples of current density-voltage $(J-V)$ curves resulting from representative devices measured under illumination are shown in Figure 2. The corresponding performance parameters such as open-circuit voltage $\left(V_{o c}\right)$, short-circuit current $\left(J_{s c}\right)$, fill factor $(F F)$ and PCE are summarized in Table 1. Also histograms in Figure S1 present the parameter distribution for the complete set of studied samples. In this respect, devices with $\mathrm{V}_{2} \mathrm{O}_{5}$ show significantly higher $P C E$ than those comprising $\mathrm{MoO}_{3}$ layers. Given that only minor improvements in the photocurrent generation and no clear trend in the $F F$ are observed, the superiority of $\mathrm{V}_{2} \mathrm{O}_{5}$-based solar cells is directly connected to the enhancement in the output $V_{o c}$ in comparison with $\mathrm{MoO}_{3}$. Illustratively, among the samples with surface texturing $\left(\mathrm{t}-\mathrm{V}_{2} \mathrm{O}_{5}\right.$ and $\left.\mathrm{t}-\mathrm{MoO}_{3}\right), \mathrm{t}-\mathrm{V}_{2} \mathrm{O}_{5}$ has a larger $J_{s c}$ while the flat sample ( $\mathrm{f}-\mathrm{V}_{2} \mathrm{O}_{5}$ ) has practically the same $J_{s c}$ as t- $\mathrm{MoO}_{3}$. Additionally, the 
$V_{\text {oc }}$ differences are apparent with significantly larger values achieved by the $\mathrm{V}_{2} \mathrm{O}_{5}$ devices. Our findings then indicate that the $\mathrm{V}_{2} \mathrm{O}_{5} / \mathrm{n}-\mathrm{Si}$ heterojunction makes up a superior contact compared to $\mathrm{MoO}_{3} / \mathrm{n}-\mathrm{Si}$.

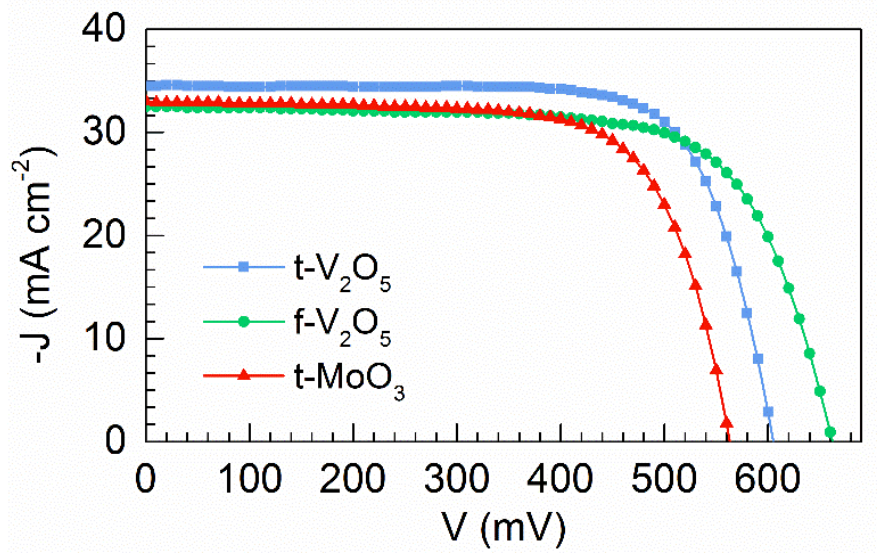

Figure 2: Experimental current density-voltage curves measured under $100 \mathrm{~mW} \cdot \mathrm{cm}^{-2}$ of AM1.5G light spectrum for different samples as indicated.

Table 1: Photovoltaic parameters corresponding to the $J-V$ curves in Figure 2 and calculated parameters from the analysis of the MS plots in Figure 3. The depletion layer width $w_{0}$ is presented at zero bias and, in parenthesis, the value calculated for the real semiconductor doping $\left(2.3 \times 10^{15} \mathrm{~cm}^{-3}\right)$. This allows comparing deviations caused by geometric effects on the capacitance area normalization.

\begin{tabular}{|c|c|c|c|c|c|c|c|}
\hline Devices & $\begin{array}{c}V_{o c} \\
(\mathrm{mV})\end{array}$ & $\begin{array}{c}J_{s c} \\
\left(\mathrm{~mA} \mathrm{~cm}^{-2}\right)\end{array}$ & $\begin{array}{c}F F \\
(\%)\end{array}$ & $\begin{array}{c}P C E \\
(\%)\end{array}$ & $\begin{array}{c}V_{b i} \\
(\mathrm{mV})\end{array}$ & $\begin{array}{c}N_{D} \\
\left(\times 10^{15} \mathrm{~cm}^{-3}\right)\end{array}$ & $\begin{array}{c}w_{0} \\
(\mathrm{~nm})\end{array}$ \\
\hline $\mathrm{t}-\mathrm{MoO}_{3}$ & 563 & 33.0 & 72.1 & 13.4 & 599 & 4.37 & $406(560)$ \\
\hline $\mathrm{t}-\mathrm{V}_{2} \mathrm{O}_{5}$ & 605 & 34.5 & 74.7 & 15.6 & 617 & 6.86 & $330(569)$ \\
\hline $\mathrm{f}^{-} \mathrm{V}_{2} \mathrm{O}_{5}$ & 662 & 32.5 & 70.6 & 15.2 & 712 & 2.10 & $644(614)$ \\
\hline
\end{tabular}

\subsection{TMO/n-Si heterojunction analysis.}

The formation of the heterojunction in the TMO/n-Si devices occurs by band bending of the n-Si energy levels producing a built-in potential $V_{b i}$. However, before entering into a discussion of the energy band diagram, it is required to explore the depletion region features in order to estimate $V_{b i}$ values exhibited by the devices. Therefore, capacitance measurements as a function of DC applied voltage in the dark were done. Figure 3 exhibits such results in the typical Mott-Schottky (MS) plot representation, i.e. $C^{-2}(V)$. The linear decrease of MS plots, as the applied voltage is swept from reverse bias to near flat band condition, evidences a constant charge density profile. Subsequently, the neutrality of charge between the negative ionized defects, presumably 
at the thin TMO side, and the positive Si ionized impurities, allow us to assume the one side abrupt junction approximation [16]. Thus the depletion layer width $w$ at the n-type silicon bulk can be calculated as a function of the applied DC bias $V$ as

$$
w=\sqrt{\frac{2 \varepsilon_{0} \varepsilon}{q N_{D}}\left(V_{b i}-V-\frac{2 k_{B} T}{q}\right)}
$$

where $q$ is the elementary charge, $k_{B}$ is the Boltzmann constant, $T$ is the absolute temperature, $\varepsilon_{0}$ is the vacuum permittivity, $\varepsilon$ is the relative dielectric constant (11.9 for $\mathrm{Si}$ ) $[16,17]$, and $N_{D}$ is the donor density (doping concentration with negligible intrinsic defects). The $2 k_{B} T / q$ term corresponds to the majority-carrier contribution in addition to the impurity concentration [16]. With this in mind, a parallel-plate capacitor model can be considered for the determination of the depletion layer capacitance per unit area as $C_{d l}=\varepsilon_{0} \varepsilon / w$. Subsequently, by substituting equation 1 and after a few operations, the simplest expression for MS analysis is obtained as

$$
C_{d l}^{-2}=\frac{2}{q \varepsilon_{0} \varepsilon N_{D}}\left(V_{b i}-V-\frac{2 k_{B} T}{q}\right) .
$$

The $V_{b i}$ can be obtained from the voltage intercept while $N_{D}$ results from the slope of the linear portion in $C^{-2}(V)$. By substituting these results in equation (1), $w$ at a given applied bias can be obtained. Resulting values for $V_{b i}, N_{D}$ and $w_{0}$ (at $V=0$ ) are reported here for the first time for TMO/c-Si solar cells, showing the expected behavior characteristic of p-n junctions (see Table 1). Regarding the band bending, it accords well with previous experimental reports via Surface Photovoltage (SPV) and theoretical simulations for the $\Phi_{n-S i}$ range $[11,18] . N_{D}$ and $w_{0}$ values in Table 1 are also in good agreement with typical orders of magnitude observed in similar structures, although they do not consider effective area rectifications and/or contributions from gap trapping states. In fact, unlike the textured samples, the presence of gap defect levels is evidenced in the $\mathrm{f}-\mathrm{V}_{2} \mathrm{O}_{5}$ device from its frequency dependent capacitance response $[19,20]$ shown in Figure S2, where the slope of the MS plot varies with the AC perturbation frequencies, even though they converge to the same $V_{b i}$ value.

MS analysis straightforwardly gives $V_{b i}$ as the intercept of the linear plots with the voltages axis, irrespective of area normalization or frequency dependent capacitances [16]. Similarly to the above mentioned $V_{o c}$ behavior, devices with $\mathrm{V}_{2} \mathrm{O}_{5}$ present higher $V_{b i}$ than those incorporating $\mathrm{MoO}_{3}$, being $\mathrm{f}-\mathrm{V}_{2} \mathrm{O}_{5}$ the structure with the larger value. Interestingly, the obtained $V_{b i}$ values are similar to those of standard c-Si solar cells in which $600-750 \mathrm{mV}$ are distributed between the two sides of the homojunction, suggesting that $\mathrm{TMO} / \mathrm{n}-\mathrm{Si}$ heterojunction behave similarly [21, 22]. The difference here is that $V_{b i} \sim 0.6-0.7 \mathrm{~V}$ is restricted to the Si side, indicating that the junction achieves weak inversion at zero bias. In addition, an almost ideal linear MS plot (Figures 3 and S2) is very much less frequent in heterojunction devices like CdTe [23, 24], CIGS [25, 26], organic [27] and hybrid [28] solar cells, where the constant doping profile (regular slope) is rarely reported. Since a constant charge density profile translates into a 
quadratic behavior of the potential within $w$, a quadratic bending of the energy bands can also be expected. These two elements (large $V_{b i}$ and constant doping) could support previous assumptions on the occurrence of a p-type inversion layer upon n-Si in the vicinity of the TMO interface (see energy-scaled band diagram of Figure 4a).

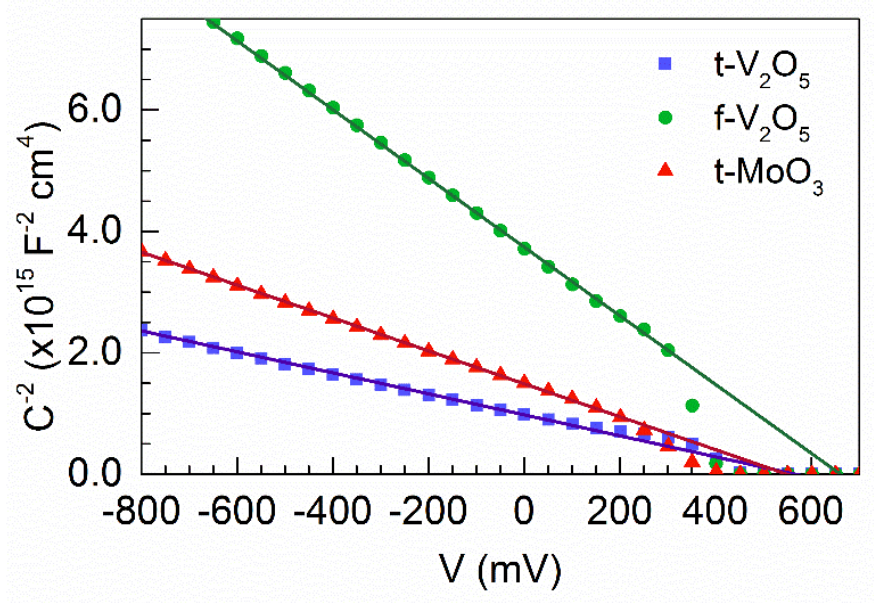

Figure 3: Experimental (dots) Mott-Schottky plots and respective linear fittings (lines) under dark and room temperature conditions for the different samples, as indicated. The AC perturbation was $10 \mathrm{mV}$ at $1.0 \mathrm{kHz}$.

As summarized in Table ST1, the studied TMOs possess large energy bandgaps and work functions compared to silicon, and generally exhibit prominent n-type conductivity due to defect states generated from oxygen vacancies [6]. This is the reason why it has been proposed $[10,15]$ that a dipole layer $\Delta$ is present at the TMO/n-Si interface, in order to equilibrate the Fermi levels in the energy band diagram once the heterojunction is formed. Considering absolute values and assuming no significant changes in the TMO electron affinity after the contact is made, this can be written as

$$
\Phi_{T M O}-\Phi_{n-S i}=q V_{b i}+\Delta \text {. }
$$

The spatial distribution of the work function offset is illustrated in Figure 4a-c in an illustrative typical case assuming $\Phi_{T M O} \sim 6.7 \mathrm{eV}$, where the interfacial dipole is possibly originated by shallow $\mathrm{O}$ vacancies in the TMO bulk $[6,10,29]$. Here, usually reported bandgaps (Table ST1) and our calculated $V_{b i}$ values (Table T1) were used to sketch energy levels before and after the formation of the heterojunction, reveling two possible scenarios. In the first case, the conduction band $\left(E_{C}\right)$ bends up forming a barrier of height $\Delta E_{C}$ of approximately $\sim 25 k_{B} T$ for electrons (Figure $4 \mathrm{~b}$ ), while in the second case no barrier is formed (Figure 4c). When such relative high barriers $\left(\Delta E_{C}>10 k_{B} T\right.$ ) are present, typically thermionic emission and/or tunneling are expected to occur [16]. Therefore, as it is known, the current density $J_{T E}$ follows the expression 


$$
J_{T E}=\frac{A T^{2}}{\alpha} \exp \left[-\frac{q \varphi}{k_{B} T}\right]\left\{\exp \left[\frac{q V}{k_{B} T}\right]-1\right\}
$$

where $k_{B} T$ is the thermal energy, $A$ is the Richardson constant, $q \varphi$ the distance between $E_{F}$ and the top of the barrier ( $q \varphi>\Delta E_{C}$ in Figure $4 \mathrm{~b}$ ), and $\alpha$ is the relation between the rest mass and the effective mass $\left(m_{0} / m^{*}\right)$ when thermionic emission over the barrier is the dominating mechanism. Thus, it can be proved [30] that the resistance unit surface $R_{0}=\left(d J_{T E} / d V\right)^{-1}$ at zero applied bias follows the relation

$$
R_{0}=\alpha \frac{k_{B}}{q A T} \exp \left[\frac{q \varphi}{k_{B} T}\right] .
$$

At this point it is useful to mention that when tunneling has a significant contributing role an extra term must be added to equation (4) and $\alpha$ can be written as a more complex expression. Furthermore, if tunneling is the dominating mechanism, $R_{0}$ cannot be easily reduced to equation (5) and the temperature should not exponentially affect $R_{0}$ . However, that situation is only expected for high doping levels above $10^{19} \mathrm{~cm}^{-3}$ [30]. Conveniently, from equation (5) it is apparent that the linear fit of $\operatorname{Ln}\left[q T R_{0} A / k_{B}\right]$ versus $q / k_{B} T$ yields an slope equaling $\varphi$ and an intercept approaching $\operatorname{Ln}[\alpha]$, allowing for testing underlying mechanisms as thermionic emission and/or tunneling across the barrier.

For this purpose, $J-V$ curves and impedance spectroscopy (IS) analyses were carried out for the textured samples $\left(\mathrm{t}-\mathrm{V}_{2} \mathrm{O}_{5}\right.$ and $\left.\mathrm{t}-\mathrm{MoO}_{3}\right)$ in the dark and within the temperature range between $210 \mathrm{~K}$ and $295 \mathrm{~K}$. The noisy response from $\mathrm{f}-\mathrm{V}_{2} \mathrm{O}_{5}$ due to its large $R_{0}$ values prevented a reliable data processing. From the studied $J$ - $V$ curves (Figures S3a,b) the slope of the linear fittings around $V=0$ was calculated and subsequently $R_{0}=(d J / d V)^{-1}$ obtained. As for the impedance, a Nyquist plot (negative imaginary part of impedance $-Z^{\prime}$ " versus the real component $Z^{\prime}$ ) [31] was obtained from the IS measurements (Figures S3c,d), and fitted to the series connection of a resistance $R_{s}$ and a simple $R C$ equivalent circuit (inset Figure S3c), being $R_{0}$ the resistance of the arc.

The $R_{0}$ values obtained from $J-V$ and $I S$ measurements can be observed in Figure S3e. With these values, Figure $4 \mathrm{~d}$ was elaborated and the barriers estimated at $q \varphi \approx 16$ meV for $\mathrm{t}-\mathrm{V}_{2} \mathrm{O}_{5}$ and $q \varphi \approx 50 \mathrm{meV}$ for $\mathrm{t}-\mathrm{MoO}_{3}$. Consequently, since such barriers are in the order of $k_{B} T$ and $\alpha \approx 10^{10}$, thermionic emission is discarded as the main transport mechanism over the barrier. This could be interpreted implying that the energy band diagram sketched in Figure $4 \mathrm{~b}$ with $\Delta E_{C}$ may occur only if tunneling is the dominating mechanism. Alternatively, it is also possible that no barrier occurs at all, as presented in the third sketch of Figure 4c. In this case, during the heterojunction formation, and due to inner bandgap defect levels, the TMO work function is augmented $\Delta \Phi_{\text {TMO }}$ as well as the dipole layer $\Delta^{\prime}=\Delta+\Delta \Phi_{\text {TMO }}$ (assuming no electron affinity change), in such a way that no interfacial barrier occurs. 

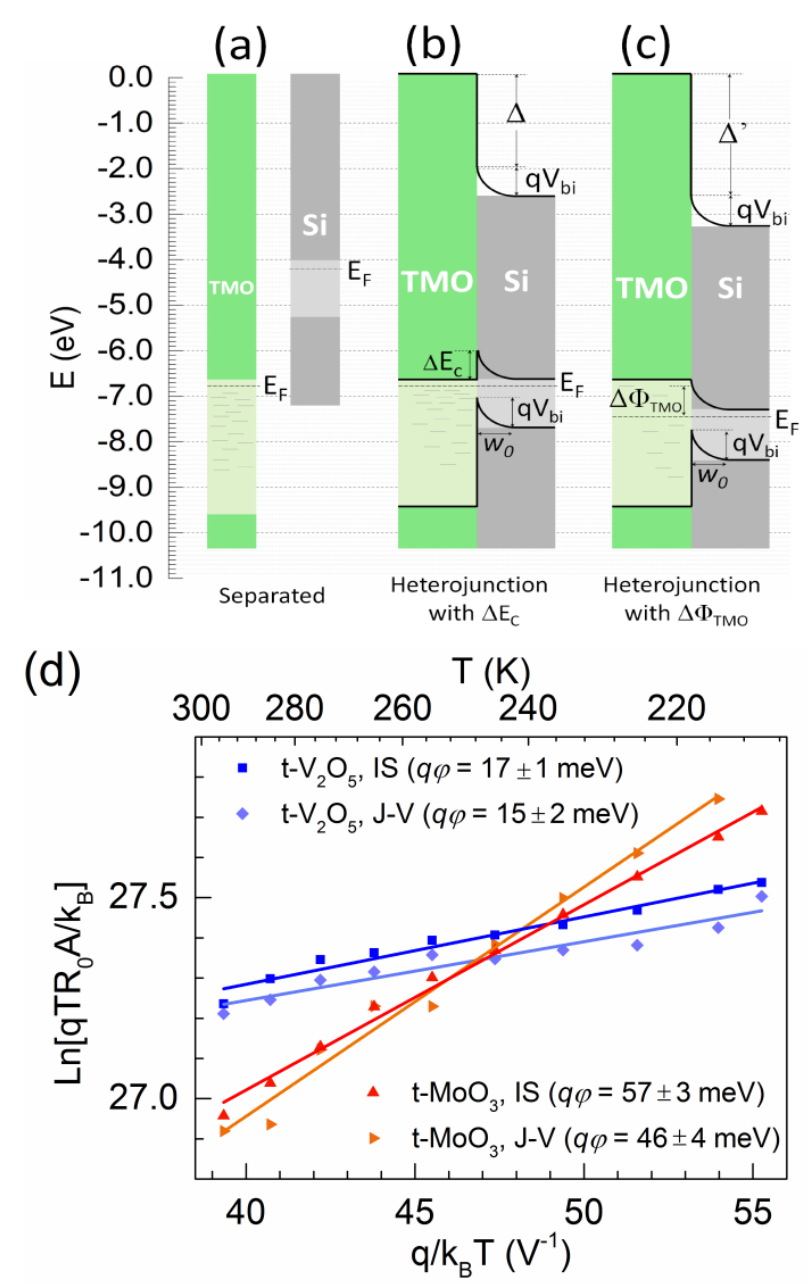

Figure 4: Energy band diagram for TMO and n-Si before contacting (a) and after the heterojunction formation with (b) and without (c) barrier formation $\Delta E_{C}$. (d) Arrhenius plot with results for possible barriers $\varphi$ for electrons. In (a) the zero signals the vacuum level and absolute values from tables T1 and ST1 were used. In (d) the data results from Figure S3 are considered. Here we propose a TMO work function enhancement $\Delta \Phi_{\text {TMO }}$ that also increases the dipole layer $\Delta$ and eliminates the barrier (c), provided that no electron affinity change occurs. This is possibly due to the absence of a barrier evidenced by the $q \varphi \approx k_{B} T$ values in (d).

Furthermore, there is also a work function scattering in Table ST1 that suggests a possible tunable conductivity in TMOs, which for $\mathrm{V}_{2} \mathrm{O}_{5}$ can reach almost the intrinsic state. The enhancement of the energetic offset between the $E_{F}$ and the TMO conduction band minimum most probably depends on the n-Si surface defects and their passivation mechanisms, which is affected by fabrication conditions and reactivity, changing the TMO work function. In addition, another recent work [15] has pointed to the formation of a $\mathrm{SiO}_{\mathrm{x} \sim 1.5}$ ultra-thin interlayer by chemical reaction between the TMO and the n-Si, as can be observed in Figure S4. This interlayer (not included in Figure 4b,c) can be directly holding the dipole or mediating the passivation. Nevertheless, work function tuning seems to be a more likely mechanism over barrier formation, at least for $\mathrm{V}_{2} \mathrm{O}_{5}-$ 
based devices. This is understood given $\mathrm{V}_{2} \mathrm{O}_{5}$ 's major $\Phi$ scattering (table ST1), their significantly higher $V_{b i}$ and $w_{0}$ values (table T1) and the absence of a noteworthy barrier (Figure 4d). Such features may have a direct impact in the recombination mechanisms as studied in the following section.

\subsection{Carrier lifetime by impedance analysis}

The differences between $\mathrm{V}_{2} \mathrm{O}_{5}$ - and $\mathrm{MoO}_{3}$-based cells are also directly reflected in the contactless photo-conductance measurements in the quasi-steady state regime (QSSPC) [32], through which minority carrier lifetime results (Figure S5). Similarly to $V_{o c}$ and $V_{b i}, \mathrm{~V}_{2} \mathrm{O}_{5}$ samples show longer carrier lifetime values. However, the QSSPC technique does not account for contact effects since it is performed before the Ag grid deposition. Accordingly, a more suitable and general protocol is presented here for studying minority carrier lifetimes in $\mathrm{TMO} / \mathrm{n}-\mathrm{Si}$ solar cells, bearing in mind that differences with respect to the QSSPC technique may respond to the TMO role in the heterojunction formation and the top electrode.

In order to explore the dominating loss mechanism in these heterojunction-based devices, i.e. the so-called Shockley-Read-Hall (SRH) recombination through interfacelocated band gap states [33], IS analysis was used. Surface recombination proceeds by electron and hole capture by surface states with subsequent annihilation. The measurements were performed under illumination at open-circuit conditions. The equivalent circuit is presented in the inset of Figure 5a, where the experimental data of $\mathrm{f}$ $\mathrm{V}_{2} \mathrm{O}_{5}$ at $V_{o c}=633 \mathrm{mV}$ is also shown with its respective fitting. The circuit is basically composed by the series connection of a resistance $R_{s}$ and two Voigt elements (parallel $R C$ subcircuit, see Figure S6) [31]. In this sense, the SRH carrier lifetime results by summing terms related to the capture rate of electrons and holes in the surface recombination center [33]. Occupancy changes of conduction band electrons and valence band holes can be accessed by exploring capacitive effect of respective excess carriers. The usually-known diffusion capacitance [16] or chemical capacitance [34] $C_{n}$ informs on the occupancy of conduction band bulk electrons [35]:

$$
C_{n}=q^{2} \frac{d n}{d E_{F_{n}}}
$$

where the capacitance is given per unit volume, $n$ corresponds to the free electron concentration and $E_{F_{n}}$ accounts for the electron quasi-Fermi level. Since at forward bias or under usual illumination levels the device can work in high-injection conditions, the occupancy change of valence band bulk holes gives rise to an additional capacitance per unit volume $C_{p}$, being $p$ the hole concentration and $E_{F_{p}}$ the hole quasi-Fermi level:

$$
C_{p}=-q^{2} \frac{d p}{d E_{F_{p}}} .
$$

Importantly, as illustrated in Figure 3, $C_{d l}$ is dominant at reverse and low forward bias regions but surpassed by $C_{n, p}$ as forward bias increases. For instance, in dark and at 
short-circuit, Figure S3f evidences the predominant depletion layer capacitance as it follows its $C_{d l} \propto T^{-1 / 2}$ trend from equation 2 .

The equivalent circuit of Figure $5 \mathrm{a}$ models the solar cell operation through the contribution of two resistive elements accounting for the individual capture of holes and electrons by the recombination centers. Surface recombination centers govern then the recombination flux through $R_{\mathrm{n}}$ and $R_{\mathrm{p}}$, which are spatially confined at the interface, while the AC response is coupled with bulk chemical capacitances of equations 6 and 7 . Consequently, the SRH carrier lifetime results by considering the separate contributions from the capture times of each carrier type as [33]

$$
\tau_{S R H}=\tau_{n}+\tau_{p}=R_{n} C_{n}+R_{p} C_{p} .
$$

Figures S7-S9 present the impedance plots with experimental data and fittings for the three solar cells under study, as well as the resulting fitting parameters for the respective $V_{o c}$ values. The behavior of $\tau_{S R H}$ values are summarized in Figure $5 \mathrm{~b}$, showing that carrier lifetime is larger for $\mathrm{V}_{2} \mathrm{O}_{5}$-based cells. This is in agreement with the results of the QSSPC technique (Figure S5), both in order of magnitude and general trend. From this comparison, and considering individual lifetime constant values (Figures S7e, S8f and S9d), it is assumed that the longer time constant corresponds to minority carriers (holes) and the shorter to the majority carriers (given that it is a n-Si base). The superior performance of $\mathrm{V}_{2} \mathrm{O}_{5}$-based cells is then connected to the reduction in surface recombination by enhanced passivation that, consequently, produces higher open-circuit voltages. Nearly one order of magnitude improvement in lifetime is observed ( 200 $\mu \mathrm{s})$ for $\mathrm{f}-\mathrm{V}_{2} \mathrm{O}_{5}$ in comparison to textured devices. In terms of effective recombination velocity, approximated as $S_{\text {eff }} \approx L / \tau_{S R H}$ being $L$ the absorber n-Si thickness, one can calculate that $S_{\text {eff }} \sim 140 \mathrm{~cm} \mathrm{~s}^{-1}\left(\mathrm{f}-\mathrm{V}_{2} \mathrm{O}_{5}\right), S_{\text {eff }} \sim 1300 \mathrm{~cm} \mathrm{~s}^{-1}\left(\mathrm{t}-\mathrm{V}_{2} \mathrm{O}_{5}\right)$, and $S_{\text {eff }} \sim 2600 \mathrm{~cm} \mathrm{~s}^{-1}$ $\left(\mathrm{t}-\mathrm{MoO}_{3}\right)$, signaling the effectiveness of the passivation strategy. By comparing $S_{\text {eff }}$ corresponding to laser firing rear structures $\left(t-\mathrm{V}_{2} \mathrm{O}_{5}\right.$ and $\left.t-\mathrm{MoO}_{3}\right)$, one can observe the beneficial effect of the textured $\mathrm{V}_{2} \mathrm{O}_{5}$ hole-selective contact. After changing the structure of both rear and front contacts $\left(f-\mathrm{V}_{2} \mathrm{O}_{5}\right)$ the performance enhancement is even larger. 

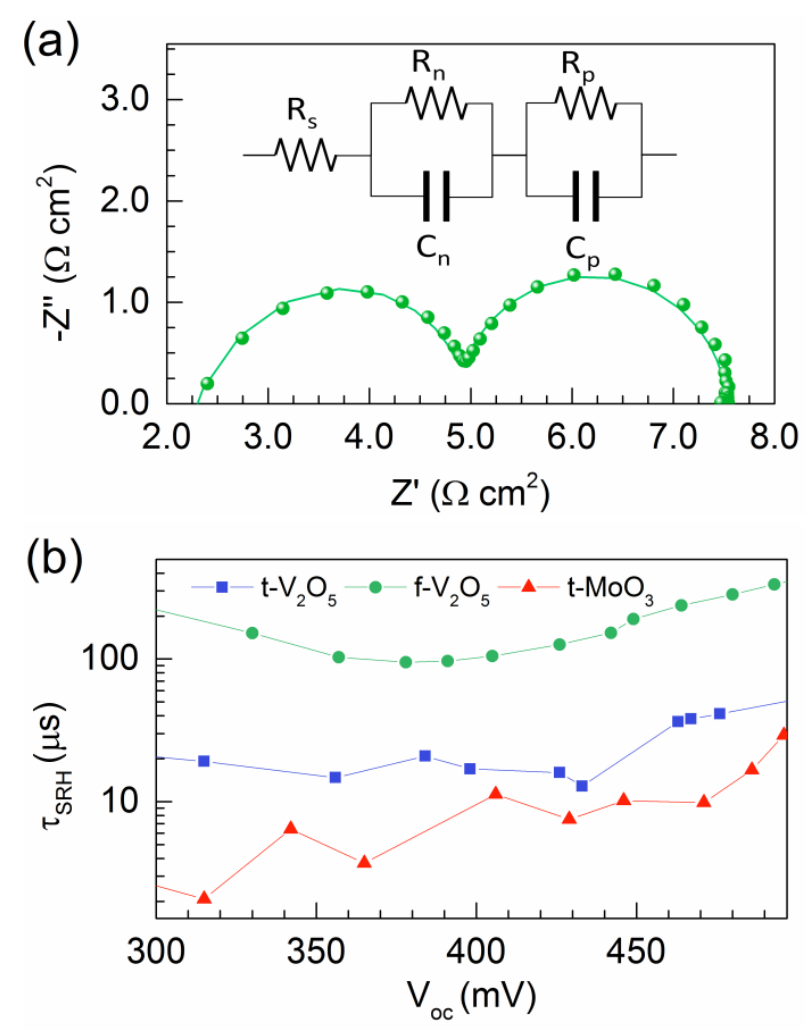

Figure 5: (a) Nyquist plot for the experimental IS results (dots) of $\mathrm{f}-\mathrm{V}_{2} \mathrm{O}_{5}$ sample at $V_{\text {oc }}=633$ $\mathrm{mV}$ with its respective fitting (solid line) to the equivalent circuit (inset). (b) Total carrier lifetime for the studied samples, as indicated.

Regarding the chemical capacitance, it is known that it follows an exponential dependence with the applied voltage $V$ (or $V_{o c}$ ) of the form $C_{n} \propto \exp \left(q V / k_{B} T\right)[16$, 34]. Accordingly, from equations 6 and 7 and taking into account how the splitting of the quasi-Fermi levels depends on the carrier concentration [36], the capacitance per unit area can be expressed as [33]

$$
C_{n, p}=\frac{q^{2} L_{n, p}}{2 k_{B} T} \frac{n_{i}^{2} \exp \left[\left(E_{F_{n}}-E_{F_{p}}\right) / k_{B} T\right]}{\sqrt{\left(N_{D} / 2\right)^{2}+n_{i}^{2} \exp \left[\left(E_{F_{n}}-E_{F_{p}}\right) / k_{B} T\right]}} .
$$

Here $n_{i}$ is the intrinsic carrier concentration, and $L_{n, p}$ stands for the effective bulk length (normal to the interface direction) of the region where the electron (or hole) occupation changes take place. This latter parameter reflects the consequent geometric differences between electrons and holes bulk capacitive behaviors due to its different recombination rates and diffusion lengths.

Moreover, the quasi-Fermi levels match the $V_{o c}$ energy (i.e. $q V_{o c}=E_{F_{n}}-E_{F_{p}}$, which is the free energy of an electron-hole pair) if infinite carrier mobility, homogeneous carrier density profiles and perfectly selective contacts are considered as good approximations [33]. Thus $C_{n, p}\left(V_{o c}\right)$ plotting should exponentially grow. Such behavior is clearly observed in Figures S7c, S8d, and S9b where the capacitances $C_{p, n}$ obtained 
from fitting are plotted as a function of $V_{o c}$.

In addition, the capacitive data of Figures S7c, S8d, and S9b were also fitted to equation 9 by using the parameters listed in Table ST2. By considering plausible $n_{i}$ levels and carrier concentrations similarly to those of Table T1, $L_{p}$ values of hundreds of micrometers were obtained for the three samples. On the other hand, $L_{n}$ of around tens of micrometers were obtained for the textured samples. Interestingly, from equation 9 a change in exponential slope from $q / k_{B} T$ to $q / 2 k_{B} T$ is expected if logarithm scaled capacitance is plotted as a function of $E_{F_{n}}-E_{F_{p}}$. As also pointed in Figures S7c, S8d, and S9b, the simulated change in exponential slope from $q / k_{B} T$ to $q / 2 k_{B} T$ can be appreciated in good agreement with the experimental data.

\section{Conclusions}

In summary, transition metal oxides $\mathrm{V}_{2} \mathrm{O}_{5}$ and $\mathrm{MoO}_{3}$ have been electrically studied as hole selective contacts in heterojunction c-Si solar cells. It has been shown that $\mathrm{V}_{2} \mathrm{O}_{5}-$ based devices have better performance than those using $\mathrm{MoO}_{3}$. While textured devices using $\mathrm{V}_{2} \mathrm{O}_{5}$ exhibit larger short-circuit currents, it was observed that flat solar cell architectures permit for a significant increase in passivation of the $\mathrm{V}_{2} \mathrm{O}_{5} / \mathrm{n}-\mathrm{Si}$ interface. This strategy allows for open-circuit voltage values reaching $662 \mathrm{mV}$. Such improvement has been supported by the exploration of the depletion layer features and the evaluation of minority carrier lifetimes. For the latter, a protocol based on IS analysis has been proposed, also revealing the important role of capacitive mechanisms in the performance of the TMO/n-Si cells. In addition, some considerations on the energy band diagram have been discussed, although some detailed aspects (such as the magnitude of dipoles involved) need to be determined in future work. Therefore, a more thorough understanding of the TMO/n-Si interface and the energetics involved could result in significant improvements for this kind of novel c-Si solar cells.

\section{Supporting Information}

Supporting Information is available from the Wiley Online Library or from the author.

\section{Acknowledgements}

We thank financial support by Ministerio de Economía y Competitividad (MINECO)

of Spain under projects MAT2016-76892-C3-1-R, ENE2013-48629-C4-1-R and ENE2014-56237-C4-1-R, and also from Generalitat Valenciana (Prometeo/2014/020). O. A. acknowledges Generalitat Valenciana for a grant (GRISOLIAP2014/035). L. G. G. acknowledges Mexico’s grant program CONACyT for a grant.

\section{References}

[1] M.A. Green, K. Emery, Y. Hishikawa, W. Warta, E.D. Dunlop, D.H. Levi, A.W.Y. Ho-Baillie, Solar Cell Efficiency Tables (version 49), Progress in Photovoltaics: Research and Applications, 25 (2017) 3-13. 
[2] C. Battaglia, A. Cuevas, S. De Wolf, High-efficiency crystalline silicon solar cells: status and perspectives, Energy Environ. Sci., 9 (2016) 1552-1576.

[3] S. De Wolf, M. Kondo, Nature of doped a-Si:H/c-Si interface recombination, J. Appl. Phys., 105 (2009) 103707.

[4] C. Battaglia, X. Yin, M. Zheng, I.D. Sharp, T. Chen, S. McDonnell, A. Azcatl, C. Carraro, B. Ma, R. Maboudian, R.M. Wallace, A. Javey, Hole Selective MoOx Contact for Silicon Solar Cells, Nano Lett., 14 (2014) 967-971.

[5] J. Bullock, M. Hettick, J. Geissbühler, A.J. Ong, T. Allen, Carolin M. SutterFella, T. Chen, H. Ota, E.W. Schaler, S. De Wolf, C. Ballif, A. Cuevas, A. Javey, Efficient Silicon Solar Cells with Dopant-Free Asymmetric Heterocontacts, Nat. Energy, 1 (2016) 15031.

[6] J. Meyer, S. Hamwi, M. Kröger, W. Kowalsky, T. Riedl, A. Kahn, Transition Metal Oxides for Organic Electronics: Energetics, Device Physics and Applications, Adv. Mater., 24 (2012) 5408-5427.

[7] F. Wang, Z.a. Tan, Y. Li, Solution-Processable Metal Oxides/Chelates as Electrode Buffer Layers for Efficient and Stable Polymer Solar Cells, Energy Environ. Sci., 8 (2015) 1059-1091.

[8] J. Geissbühler, J. Werner, S. Martin de Nicolas, L. Barraud, A. Hessler-Wyser, M. Despeisse, S. Nicolay, A. Tomasi, B. Niesen, S. De Wolf, C. Ballif, 22.5\% Efficient Silicon Heterojunction Solar Cell with Molybdenum Oxide Hole Collector, Appl. Phys. Lett., 107 (2015) 081601.

[9] James Bullock, Christian Samundsett, Andres Cuevas, Di Van, Y. Wan, T. Allen, Proof-of-concept p-type silicon solar cells with molybdenum oxide partial rear contacts, in: 2015 IEEE 42nd Photovoltaic Specialist Conference (PVSC), IEEE, 2015.

[10] L.G. Gerling, S. Mahato, A. Morales-Vilches, G. Masmitja, P. Ortega, C. Voz, R. Alcubilla, J. Puigdollers, Transition Metal Oxides as Hole-Selective Contacts in Silicon Heterojunctions Solar Cells, Sol. Energy Mater. Sol. Cells, 145, Part 2 (2016) 109-115.

[11] M. Bivour, J. Temmler, F. Zähringer, S. Glunz, M. Hermle, High Work Function Metal Oxides for the Hole Contact of Silicon Solar Cells, in: 2016 IEEE 43rd Photovoltaic Specialists Conference (PVSC), IEEE, Portland, OR, USA, 2016, pp. 0215-0220.

[12] W. Wu, J. Bao, X. Jia, Z. Liu, L. Cai, B. Liu, J. Song, H. Shen, Dopant-Free Back Contact Silicon Heterojunction Solar Cells Employing Transition Metal Oxide Emitters, Phys. Status Solidi RRL, 10 (2016) 662-667.

[13] J. Bullock, A. Cuevas, T. Allen, C. Battaglia, Molybdenum oxide MoOx: A versatile hole contact for silicon solar cells, Appl. Phys. Lett., 105 (2014) 232109. 
[14] M. Colina, A.B. Morales-Vilches, C. Voz, I. Martín, P.R. Ortega, R. Alcubilla, Low Surface Recombination in Silicon-Heterojunction Solar Cells With Rear LaserFired Contacts From Aluminum Foils, IEEE J. Photovoltaics, 5 (2015) 805-811.

[15] L.G. Gerling, C. Voz, R. Alcubilla, J. Puigdollers, Origin of Passivation in HoleSelective Transition Metal Oxides for Crystalline Silicon Heterojunction Solar Cells, J. Mater. Res., 32 (2016) 260-268.

[16] S.M. Sze, K.K. Ng, Physics of Semiconductor Devices, 3rd ed., John Wiley \& Sons, Hoboken, New Jersey, USA, 2007.

[17] G.A. Samara, Temperature and Pressure Dependences of the Dielectric Constants of Semiconductors, Phys. Rev. B, 27 (1983) 3494-3505.

[18] M. Bivour, B. Macco, J. Temmler, W.M.M. Kessels, M. Hermle, Atomic Layer Deposited Molybdenum Oxide for the Hole-selective Contact of Silicon Solar Cells, Energy Procedia, 92 (2016) 443-449.

[19] R. Herberholz, M. Igalson, H.W. Schock, Distinction Between Bulk and Interface States in $\mathrm{CuInSe}_{2} / \mathrm{CdS} / \mathrm{ZnO}$ by Space Charge Spectroscopy, J. Appl. Phys., 83 (1998) 318-325.

[20] T. Walter, R. Herberholz, C. Müller, H.W. Schock, Determination of Defect Distributions from Admittance Measurements and Application to $\mathrm{Cu}(\mathrm{In}, \mathrm{Ga}) \mathrm{Se}_{2}$ Based Heterojunctions, J. Appl. Phys., 80 (1996) 4411-4420.

[21] I. Mora-Sero, G. Garcia-Belmonte, P.P. Boix, M.A. Vazquez, J. Bisquert, Impedance spectroscopy characterisation of highly efficient silicon solar cells under different light illumination intensities, Energy Environ. Sci., 2 (2009) 678-686.

[22] A.F. Braña, E. Forniés, N. López, B.J. García, High Efficiency Si Solar Cells Characterization Using Impedance Spectroscopy Analysis, Journal of Physics: Conference Series, 647 (2015) 012069.

[23] J.V. Li, A.F. Halverson, O.V. Sulima, S. Bansal, J.M. Burst, T.M. Barnes, T.A. Gessert, D.H. Levi, Theoretical analysis of effects of deep level, back contact, and absorber thickness on capacitance-voltage profiling of CdTe thin-film solar cells, Solar Energy Materials and Solar Cells, 100 (2012) 126-131.

[24] O. Almora, L. Vaillant-Roca, A. Bosio, Electrical Characterizations of CdTe/CdS Poly-Crystalline Thin Film Solar Cells, Rev. Cuba Fis., 31 (2014) 66-70.

[25] P.J. Sebastian, M.E. Calixto, R.N. Bhattacharya, R. Noufi, CIS and CIGS Based Photovoltaic Structures Developed from Electrodeposited Precursors, Sol. Energy Mater. Sol. Cells, 59 (1999) 125-135.

[26] T. Eisenbarth, T. Unold, R. Caballero, C.A. Kaufmann, H.-W. Schock, Interpretation of Admittance, Capacitance-Voltage, and Current-Voltage Signatures in Cu(In,Ga)Se $e_{2}$ Thin Film Solar Cells, J. Appl. Phys., 107 (2010) 034509. 
[27] P.P. Boix, J. Ajuria, I. Etxebarria, R. Pacios, G. Garcia-Belmonte, J. Bisquert, Role of ZnO Electron-Selective Layers in Regular and Inverted Bulk Heterojunction Solar Cells, J. Phys. Chem. Lett., 2 (2011) 407-411.

[28] O. Almora, C. Aranda, E. Mas-Marzá, G. Garcia-Belmonte, On Mott-Schottky Analysis Interpretation of Capacitance Measurements in Organometal Perovskite Solar Cells, Appl. Phys. Lett., 109 (2016) 173903.

[29] Y. Guo, J. Robertson, Origin of the High Work Function and High Conductivity of $\mathrm{MoO}_{3}$, Appl. Phys. Lett., 105 (2014) 222110.

[30] B. Ghosh, Electrical Contacts for II-VI Semiconducting Devices, Microelectron. Eng., 86 (2009) 2187-2206.

[31] V.F. Lvovich, Impedance Spectroscopy. Applications to Electrochemical and Dielectric Phenomena, John Wiley \& Sons, Inc., Hoboken, New Jersey, 2012.

[32] R.A. Sinton, A. Cuevas, Contactless Determination of Current-Voltage Characteristics and Minority-Carrier Lifetimes in Semiconductors from Quasi-SteadyState Photoconductance Data, Appl. Phys. Lett., 69 (1996) 2510-2512.

[33] I. Mora-Seró, Y. Luo, G. Garcia-Belmonte, J. Bisquert, D. Muñoz, C. Voz, J. Puigdollers, R. Alcubilla, Recombination Rates in Heterojunction Silicon Solar Cells Analyzed by Impedance Spectroscopy at Forward Bias and Under Illumination, Sol. Energy Mater. Sol. Cells, 92 (2008) 505-509.

[34] J. Bisquert, Nanostructured Energy Devices: Equilibrium Concepts and Kinetics, CRC Press Taylor \& Francis Group, Boca Raton, 2014.

[35] J. Bisquert, D. Cahen, G. Hodes, S. Rühle, A. Zaban, Physical Chemical Principles of Photovoltaic Conversion with Nanoparticulate, Mesoporous DyeSensitized Solar Cells, J. Phys. Chem. B, 108 (2004) 8106-8118.

[36] R. Brendel, Thin-Film Crystalline Silicon Solar Cells: Physics and Technology, Wiley-VCH Verlag GmbH \& Co. KGaA, Weinheim, 2003. 